The American Journal of Gastroenterology 112, 971-972 (June 2017) | doi:10.1038/ajg.2017.86

Volume 112, Issue 6 (June 2017)

- The American Journal of Gastroenterology

- ISSN: 0002-9270

- EISSN: 1572-0241

\title{
Wild Mushrooms: An Exclusive Delicacy or Last Meal
}

Andon Chibishev, Milka Zdravkovska and Mirjana Jankulovska

\section{Abstract}

To the Editor: Poisonings due to wild mushrooms have been known since ancient times; the first death as a result of their toxicity was described 450 years $\mathrm{BC}$, and since then we have identified more than $\mathbf{5 0 0 0}$ different kinds of mushrooms, with hundreds of them registered as poisonous. Ingestion of several types of wild mushrooms can lead to an urgent clinical state and development of various symptoms of which the most dangerous are severe impairment in renal and liver functions $(1,2)$.

\section{Impact factor}

2016 Impact Factor 9.566*

Rank:

6/79 Gastroenterology \& Hepatology

*2016 Journal Citation Reports ${ }^{\circledR}$ Science Edition (Clarivate Analytics, 2017)

\section{Abstracted/Indexed In}

BIOSIS

Current Contents/Clinical Medicine

Science Citation Index SciSearch/SCI Expanded

EMBASE/Excerpta Medica 
Elsevier BIOBASE/Current Awareness in Biological Sciences

Index Medicus

Research Information Systems/Reference Update

Biological Abstract

Chemical Abstracts

CAB Abstracts

Global Health

Derwent Journals Abstracted

PASCAL

\section{ISSN and eISSN}

The international standard serial number (ISSN) for The American Journal of Gastroenterology is 0002-9270 and the electronic standard serial number (eISSN) is 1572-0241. 